\title{
Modelagem Matemática: concepções de licenciandos em formação inicial
}

\author{
Luiz Otávio Rodrigues Mendes \\ Emilly Gonzales Jolandek \\ Ana Lúcia Pereira
}

\section{Resumo}

O presente artigo apresenta um relato de prática sobre Modelagem Matemática (MM) realizada com licenciandos do $3^{\mathrm{o}}$ ano do Curso de Licenciatura em Matemática da Universidade Estadual de Ponta Grossa (UEPG)/PR. As atividades desenvolvidas foram baseadas em duas modelagens: I - calcular a área do corpo humano e II - relação da numeração do calçado com o tamanho do pé, onde os alunos foram estimulados a participar ativamente desse processo. $\mathrm{O}$ trabalho teve como objetivo inserir o tema MM no contexto de formação inicial de professores, pensando em como ela pode ser utilizada enquanto uma metodologia que pode ser empregada na sala de aula. A principal lição extraída dessa experiência foi a efetividade da metodologia de $\mathrm{MM}$ em aprimorar o conhecimento matemático utilizado em cada uma das modelagens, a criatividade e a colaboração entre os licenciandos, tornando a aprendizagem mais significativa. Nossos dados apontam ainda que é preciso um investimento maior no uso de metodologias diferenciadas durante a formação inicial de professores.

Palavras-chave: Modelagem Matemática. Ensino. Práticas Pedagógicas. Formação de Professores. 


\section{Introdução}

Apresentamos aqui os resultados de uma experiência sobre MM, realizada através de duas oficinas na disciplina de Instrumentação para o Ensino da Matemática III, com alunos do terceiro ano do curso de Licenciatura em Matemática da Universidade Estadual de Ponta Grossa (UEPG).

O trabalho teve como objetivo inserir o tema MM no contexto de formação inicial de professores, pensando em como ela pode ser utilizada enquanto uma metodologia a ser empregada na sala de aula, podendo ainda proporcionar um aprendizado diferenciado e significativo para os alunos. Dessa forma, cabe aos professores formadores apresentá-la como uma das diferentes formas para se ensinar Matemática.

Além de apresentar o relato de prática, o presente trabalho também tem como objetivo analisar as concepções dos licenciandos em Matemática que vivenciaram essa experiência, sobre o que é a MM. Buscamos ainda analisar como se deu a interação e a construção do conhecimento por parte dos licenciandos em relação à MM, após essa experiência, e apontar como a Modelagem pode auxiliar no processo de ensino e aprendizagem na Educação Matemática.

\section{A utilização da Modelagem Matemática na formação de professores}

O Brasil é um país megadiverso, possuindo com isso uma diversidade multicultural que reflete em nossas salas de aula. Diante disso, os PCN (Parâmetros Curriculares Nacionais) destacam que o professor precisa estar preparado para enfrentar essa realidade, buscando incentivar os alunos a questionar a sua realidade, conjecturando, levantando hipóteses, formulando problemas, como um sujeito ativo e participativo (BRASIL, 1997). Por isso, a formação do professor tem um papel importantíssimo, para que ele se sinta seguro em buscar e realizar formas diferenciadas de ensinar. Isso compreende também levar em consideração o cotidiano do aluno, buscando desenvolver, aplicar problemas com situações reais e com soluções na linguagem cotidiana do aluno.

Esse contexto de aprendizagem é chamado por Bassanezi (2002) de Modelagem Matemática, que possibilita o ensino de conteúdos matemáticos conectados com outras formas de conhecimento. Para Burak (1987, p.62), a MM é um "conjunto de procedimentos cujo objetivo é construir um paralelo para tentar explicar matematicamente os fenômenos presentes no cotidiano do ser humano, ajudando-o a fazer predições e a tomar decisões”, mostrando com isso o quanto é importante poder utilizar esse aparato no processo de ensino e aprendizagem do aluno.

A Modelagem utiliza modelos matemáticos para formular, descrever, delinear e representar matematicamente situações-problemas de fenômenos presentes no dia a dia. 
Almeida e Dias (2003) ressaltam a importância de introduzir atividades de Modelagem nos cursos de Licenciatura em Matemática por meio das disciplinas específicas ou em outras disciplinas do currículo, com o propósito de propiciar aos futuros professores experiências e diferentes concepções em relação ao uso da MM em sua futura prática docente.

Tanto na Educação Básica quanto na Educação Superior o professor deve estimular o aluno para que o mesmo tenha interesse pela disciplina e pelos conteúdos específicos. Entretanto, esse trabalho deve iniciar-se desde as séries iniciais, com os conteúdos considerados mais básicos, onde devem ser ensinados de forma profunda, mas ao mesmo tempo atrativa aos olhos do educando, para que este adquira uma aprendizagem completa (WHITE, 2007).

White (2007) destaca ainda que o professor deve buscar colocar em prática, na sua vivência, os estudos teóricos e o que aprende durante a sua formação. À medida que coloca em prática o seu conhecimento, aumenta seu potencial cognitivo. Assim terá o privilégio de colher a cada dia resultados visíveis de suas aulas em relação ao aprendizado do educando. A autora destaca ainda que o professor "deve constantemente ter como objetivo a simplicidade e a eficiência. Deve fazer grande uso de ilustrações ao ensinar; e mesmo tratando de alunos mais velhos cumpre ter o cuidado de tornar claras e evidentes todas as explicações. Muitos alunos adiantados em idade são crianças no entendimento" (WHITE, 2007, p.233).

Utilizar formas diferenciadas de ensino, como a MM, também deve ocorrer nos cursos de formação de professores, pois os licenciandos têm a necessidade de um aprendizado rico e de qualidade, onde possam desenvolver o raciocínio e fazer relação entre os conceitos aprendidos, para que quando estiverem desenvolvendo a prática profissional consigam aplicar os conhecimentos construídos, adquiridos, na construção dos saberes dos alunos. Bassanezi (2002, p.38) ressalta que:

A modelagem no Ensino é apenas uma estratégia de aprendizagem, onde o mais importante não é chegar imediatamente a um modelo bem-sucedido, mas caminhar seguindo etapas onde o conteúdo matemático vai sendo sistematizado e aplicado. Com a modelagem o processo de ensinoaprendizagem não mais se dá no sentido único do professor para o aluno, mas como resultado da interação do aluno com seu ambiente natural.

Segundo Klüber e Burak (2008), o trabalho realizado com a MM sempre ocorre em plena interação com professor, aluno e ambiente. $\mathrm{O}$ aluno deve pesquisar, o professor faz o papel de mediador, deixando o aluno desenvolver a sua autonomia, e o ambiente é a origem de toda a pesquisa, sem nenhum querer dominar o outro. Destacamos isso porque atualmente, em muitas instituições, ainda encontramos um modelo de ensino em que o professor é visto 
como o detentor do conhecimento, ensinando exatamente da forma como lhe foi ensinado, cabendo ao aluno toda a responsabilidade pelo aprender.

Portanto, pensar em inverter esse modelo de formação inclui levar em consideração as novas metodologias de ensino na educação, desde a formação inicial do professor. Por isso, neste trabalho destacamos a MM como uma diferenciada tendência metodológica de ensino. Segundo Meyer et al. (2011, p.28), temos cinco momentos para o processo de Modelagem:
a) Determinar a situação;
b) Simplificar as hipóteses dessa situação;
c) Resolver o problema matemático decorrente;
d) Validar as soluções matemáticas;
e) Definir a tomada de decisão com base nos resultados.

O autor destaca que, ao realizarmos uma aplicação de Modelagem Matemática, cada uma dessas etapas pode acontecer de forma independente, mas deve estar ligada às bases desses cinco momentos.

\section{Desenvolvimento}

Como destacamos anteriormente, para alcançarmos os nossos objetivos de pesquisa no presente trabalho, realizamos duas atividades de MM com uma turma de $3^{\circ}$ Ano do Curso de Licenciatura em Matemática da Universidade Estadual de Ponta Grossa/PR. A primeira MM estava relacionada com o cálculo da área do corpo humano, e a segunda sobre a relação existente entre o número do calçado e o tamanho dos pés. A primeira aplicação da situaçãoproblema foi dividida em duas partes. A primeira buscava calcular a área do corpo humano, ou seja, a quantidade aproximada de pele que o corpo humano tem.

A primeira MM aqui apresentada, também foi realizada por um dos autores desse artigo (BACCON; ARRUDA, 2004) em uma turma do $6^{\circ}$ ano do Ensino Fundamental da rede pública na disciplina de Laboratório de Matemática. Nessa ocasião os autores buscaram analisar as mudanças ocorridas nas concepções dos alunos, após o uso dessa nova metodologia.

Os autores destacam que a análise dos resultados permitiu considerar que a MM pode propiciar a construção de uma aprendizagem mais significativa e prazerosa para o aluno, e também "demonstram avanços qualitativos nos procedimentos metodológicos utilizados pelo professor" (BACCON; ARRUDA, 2004, p.11).

Para realizar essa prática foi montado o esboço de um boneco com cada parte do corpo relacionada a sólidos geométricos. Dessa forma, cada parte do corpo (cabeça, pescoço, braços, pernas, tórax etc.) era considerada como um cilindro, que na forma plana seria correspondente à área do retângulo. Portanto, para encontrar a quantidade de pele de cada ISSN 2526-2882 
parte do corpo, os alunos calculavam a área de cada parte multiplicando o comprimento pela largura.

Figura 1 - Esboço do boneco com as partes do corpo como se fossem sólidos geométricos

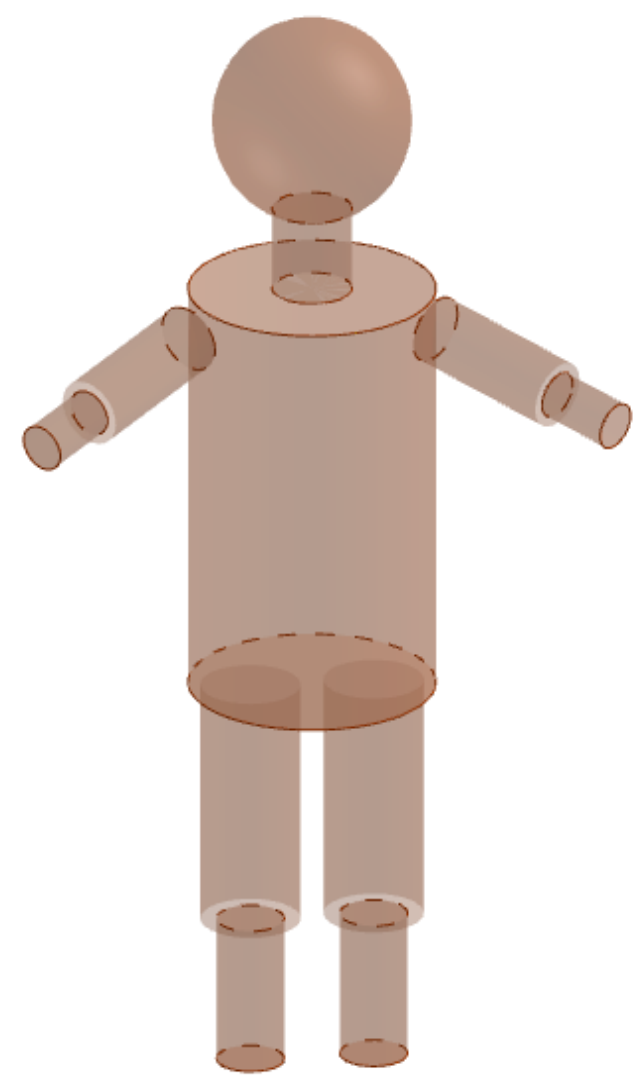

Fonte: Produção Própria

Para achar a quantidade de pele de uma parte do corpo, bastava calcular a área de Qi = ci $x$ li. A quantidade total de pele (tecido epitelial) do corpo é a soma da quantidade de pele de cada parte. Assim como Baccon e Arruda (2004), definimos as seguintes variáveis:

$>\mathrm{Q}=$ quantidade total de pele do corpo

$>\mathrm{Li}=$ largura da parte i de seu corpo

$>\mathrm{Ci}=$ comprimento da parte i de seu corpo

$>\mathrm{Qi}=$ quantidade de pele da parte i de seu corpo

Após relembrarem as fórmulas de cálculo da área dos sólidos geométricos, em duplas, cada aluno ajudou o colega a tirar as suas medidas, marcando-as em uma tabela para calcular a área de cada parte do seu corpo. 
Tabela 1 - Medidas de cada parte do corpo

\begin{tabular}{|l|l|l|l|l|l|l|l|l|l|l|l|l|l|l|l|l|l|l|}
\hline \multirow{2}{*}{$\begin{array}{l}\text { Nomes } \\
\text { dos } \\
\text { alunos }\end{array}$} & 1- Cabeça & \multicolumn{2}{|l|}{ 2- Pescoço } & 3- Tronco & 4- Braço 1 & 5- Braço 2 & \multicolumn{2}{|l|}{ 6- Perna 1 } & \multicolumn{2}{|l|}{ 7- Perna 2 } \\
\hline & i & i & i & i & i & i & i & i & i & i & i & i & i \\
\hline & & & & & & & & & & & & & & \\
\hline & & & & & & & & & & & & & & \\
\hline
\end{tabular}

Fonte: Produção Própria

A quantidade de pele total do corpo pode ser obtida somando a área de cada parte. Com o objetivo de organizar os dados, os alunos preencheram a Tabela 2:

Tabela 2 - Quantidade de pele de cada parte do corpo

\begin{tabular}{|l|l|l|l|l|l|l|l|}
\hline Nomes dos alunos & Q1 & Q2 & Q3 & Q4 & Q5 & Q6 & Q7 \\
\hline & & & & & & & \\
\hline & & & & & & & \\
\hline & & & & & & & \\
\hline
\end{tabular}

Fonte: Produção Própria

Ao somarem todas as partes para obter quanto cada pessoa tem de pele em seu corpo, os alunos construíram o seguinte modelo:

$$
\mathbf{Q}=\mathbf{Q 1}+\mathbf{Q 2}+\mathbf{Q 3}+\mathbf{Q 4}+\mathbf{Q 5}+\mathbf{Q 6}+\mathbf{Q 7}
$$

Na segunda parte dessa atividade, após todos os alunos terem calculado a área do seu corpo e comparado com as dos colegas, foi solicitado que cada um encontrasse a área do seu pé em uma folha de papel quadriculado, com quadrados de $1 \mathrm{~cm}$ de lado. Com esse resultado em mãos, foi solicitado aos alunos que comparassem a área do seu corpo com a área do seu pé. Com essa atividade os alunos puderam perceber que existe uma relação entre área do pé e área do corpo, ou seja, que a área de cada pé é aproximadamente $5 \%$ da área do corpo.

Em outro momento foi proposto aos alunos a segunda situação-problema que consistia em verificar a relação entre o número do sapato e o tamanho dos pés. Para contextualizar esse tema, apresentamos um pouco da história que envolve essa situação e suas variações em diferentes países, explicando o fato histórico que houve com o passar dos tempos, e como foram se adaptando até chegarem aos dias atuais.

Nessa atividade os licenciandos também trabalharam em duplas, onde um ajudava o 
outro a contornar o tamanho dos pés em uma folha de papel, coletando assim as medidas em centímetros no sentindo dos dedos ao calcanhar. Após a coleta dessa medida, os alunos também marcaram o número que cada um deles calçava. De posse dessas medidas, os alunos criaram um plano cartesiano, colocando na reta horizontal (das abscissas) os valores do tamanho dos calçados, e na reta vertical (das ordenadas), o valor do tamanho dos pés.

Dessa prática puderam analisar o conhecimento matemático implícito na atividade, ao traçar as retas com os dados de cada aluno. Com o acompanhamento do professor conseguiram visualizar a fórmula geral da reta e obter a fórmula, o "modelo" para calcular o número do sapato em relação ao tamanho do pé, onde $\mathbf{N}$ é o número do sapato e $\mathbf{p}$ é o tamanho do pé em centímetros.

$$
\mathrm{N}=(5 \mathrm{p}+\mathbf{2 8}) / 4
$$

Almeida, Araújo e Bisognin (2011) destacam que a situação final na MM é a aquisição de um conhecimento, representando a solução da problemática. No nosso caso, na primeira atividade, seria levar os alunos a alcançar o aprendizado relacionado à área do corpo humano com a área dos sólidos geométricos e na segunda atividade seria perceber a relação do tamanho do pé com a numeração do sapato com a fórmula da equação geral da reta.

Após o desenvolvimento das duas atividades de MM, aplicamos um questionário aos licenciandos composto por perguntas abertas relativas às aplicações, para serem analisadas posteriormente. Assim como Baccon e Arruda (2004), buscamos também analisar as mudanças ocorridas nas concepções dos alunos, após o uso dessa nova metodologia. $\mathrm{Na}$ próxima seção apresentamos como se deu a organização e tratamento desses dados.

\section{Resultados e discussões}

Como dissemos acima, depois das práticas realizadas em sala de aula, aplicamos um questionário que é uma técnica de investigação (GIL, 1999), contendo cinco questões com perguntas abertas para identificarmos as concepções dos alunos sobre MM e como caracterizaram as atividades desenvolvidas nesse contexto.

Os sujeitos participantes da pesquisa são dezessete licenciandos do terceiro ano do curso de Licenciatura em Matemática. A fim de preservar a identidade dos licenciandos, os mesmos serão representados pela letra "L" seguida por um número que indica a quantidade de respondentes (L1, L2, L3, ... L17).

A organização dos dados foi construída a partir das respostas dos licenciandos para as perguntas do questionário: O que você entende por Modelagem Matemática? O que você achou da primeira Modelagem Matemática (área do corpo humano)? O que você achou da ISSN 2526-2882 
segunda Modelagem Matemática (número do sapato)? O que mais te chamou atenção? Você já tinha realizado alguma Modelagem Matemática antes?

Para a organização dos dados nessa etapa, utilizamos o software Atlas.ti ${ }^{1}$ versão 7.0. A partir daí realizamos a categorização e análise dos dados através da Análise de Conteúdo de Bardin (2011). Assim, a interpretação dos dados coletados foi organizada em três momentos principais: pré-análise, exploração do material e posterior tratamento dos resultados, com possibilidade de inferências e interpretações.

A organização dos dados materializou-se com a apresentação das unidades de análises geradas pelas respostas dos licenciandos pesquisados, de onde foi possível construirmos quatro categorias que são apresentadas na seção seguinte.

\section{Categoria I - Interessante}

A categoria I reúne os trechos das falas dos licenciandos que apontaram a atividade de MM como "interessante". As falas representativas dessa categoria foram encontradas em $65 \%$ das falas dos licenciandos, de onde podemos inferir que os mesmos consideraram as oficinas de MM como interessantes e apropriadas para serem aplicadas em sala na Educação Básica, principalmente, por serem trabalhadas em grupo, envolvendo vários conteúdos matemáticos e, ainda, porque instigam o aluno, pois são curiosidades que muitas vezes o educando não percebe que há matemática envolvida. Vejamos como os licenciandos destacam essa questão:

L10 - Foi uma atividade interessante, que pode ser aplicada em salas de aula e que haverá um maior interesse dos alunos, pois é algo de certa forma curioso e que muitos não imaginariam que a Matemática poderia estar ligada.

L3 - Interessante para trabalhar com alunos em sala, pois envolve a ideia de área e proporção.

L13 - Interessante, é uma forma diferente de ser trabalhada, ou seja, sai fora do comum e nos aproxima das pessoas ao nosso redor.

L12 - Foi muito interessante, pois podemos ligar o real com a sala de aula, em relação de como as empresas fazem para fazer os sapatos.

L17 - Interessante e importante, pois é uma atividade que possibilita trabalhar com diversos conteúdos e chama atenção dos discentes, de forma a tornar a aula diferenciada. Mostra aos alunos que há mais de uma forma para resolver alguns problemas.

O desempenho foi visivelmente plausível em ambas as oficinas, sendo que os acadêmicos demonstraram interesse em conhecer mais sobre essa tendência

\footnotetext{
${ }^{1}$ O software Atlas.ti consiste em uma ferramenta para a análise de dados qualitativos que pode facilitar o gerenciamento e a interpretação dos mesmos. Este software teve sua primeira edição comercial lançada em 1993 e, partir de então, passou a ser empregado por diferentes áreas de conhecimento. [...] O objetivo do software é desenvolver uma ferramenta que apoie e facilite a interpretação humana (WALTER; BACH, 2009, p. 3).
} ISSN 2526-2882 
matemática. Na visão de Bassanezi (2002, p.16), a MM “deve residir no fato de poder ser tão agradável quanto interessante. Nessa nova forma de encarar a matemática, a Modelagem que pode ser tomada tanto como um método científico de pesquisa quanto como uma estratégia de ensino-aprendizagem tem se mostrado muito eficaz”.

O trabalho com a Modelagem proporciona "situações motivadoras, desafiadoras e interessantes de ensino" (GONÇALVES; BRITO, 2001, p.223) e, consequentemente, também na aprendizagem, como pudemos ver nos relatos dos alunos.

\section{Categoria II - Encontrar um modelo para solucionar problemas reais}

$\mathrm{Na}$ categoria II, elencamos as falas dos alunos que apontaram que a MM está relacionada a "Encontrar um modelo para solucionar problemas reais". As unidades de análises representativas dessa categoria foram encontradas em $59 \%$ das falas dos licenciandos, que entendem que a MM é encontrar um modelo para solucionar problemas reais do cotidiano. Essa categoria vai ao encontro do que Bassanezi (2002) destaca ao apontar que a "Modelagem Matemática consiste na arte de transformar problemas da realidade em problemas matemáticos e resolvê-los interpretando suas soluções na linguagem do mundo real” (BASSANEZI, 2002, p.16). Vejamos como alguns licenciandos destacam isso em suas falas:

\footnotetext{
L3 - Modelar uma situação real do dia a dia em uma forma Matemática para trabalhar em sala.

L8 - Parece-me um modelo após uma situação real, concreta, cotidiana. E como num modelo físico observamos um evento e podemos modelá-lo matematicamente.

L9 - É modelar situações, objetos do dia a dia de forma Matemática. Trazer uma problematização de forma que possa ser resolvida matematicamente.

L17 - Uma tendência metodológica que surgiu com a Educação Matemática, onde o objetivo é encontrar um modelo para problemas reais.
}

Com a realização das oficinas, os alunos puderam vivenciar na prática o conceito do que era a MM e isso pode ser observado nas falas dos mesmos, indo ao encontro do que Burak (1987, p.62) apresenta para a modelagem, como uma tentativa de "explicar matematicamente os fenômenos presentes no cotidiano do ser humano" e por Bassanezi (2002) como uma possibilidade de ensinar os conteúdos matemáticos conectados com outras formas de conhecimentos. 


\section{Categoria III - Cálculo simplificado que a Modelagem apresenta}

A categoria III foi construída a partir dos fragmentos das falas dos licenciandos centrados na ideia de que na MM o cálculo é simplificado. Essa categoria está relacionada àquilo que mais chamou a atenção dos licenciandos nas oficinas realizadas. As unidades de análises representativas dessa categoria somam $41 \%$, indicando que acharam que o cálculo na MM se apresenta de forma simplificada.

L2 - A obtenção dos resultados por métodos simples que a Modelagem Matemática apresenta.

L14 - As relações que obtive por meio de cálculos simples.

L16 - Os cálculos que obtivemos através de contas do cotidiano.

As atividades propostas aos licenciandos não possuíam um alto nível de dificuldades, e por isso acreditávamos que os cálculos para a maioria dos discentes seriam simples. Durante a realização das atividades foi possível perceber que MM proporciona uma maior interação entre os alunos, ao buscarem solucionar problemas reais do dia a dia. Percebe-se também que os alunos se sentiam motivados a pensar e a construir conceitos matemáticos e demonstraram uma maior autonomia em relação ao conteúdo matemático, dando a ideia de que o cálculo é mais simplificado. Isso vai ao encontro do que Machado (2005) destaca quando as atividades de MM são desenvolvidas em sala de aula, dizendo que elas:

Proporcionam a construção de conceitos com sentido, porque, partindo de problemas reais que conferem utilidade à matemática já aprendida, estarão relacionando a linguagem simbólica própria da matemática com a linguagem textual de uma situação real problematizada (MACHADO, 2005, p.100).

Podemos destacar ainda que a MM proporciona aos discentes um ambiente de aprendizagem significativa, possibilitando discussões que ajudam na construção do conhecimento.

\section{Categoria IV - Demonstrar fenômenos matematicamente}

$\mathrm{Na}$ categoria IV foram reunidos os fragmentos de análises onde os licenciandos se reportam para a importância da MM, principalmente por demonstrar fenômenos matematicamente. Essa categoria foi construída com as unidades de análise identificada em $23 \%$ das falas dos licenciandos. Vejamos algumas falas representativas dessa categoria:

L2 - Algo a ser explorado, pesquisado, a simulação de coisas reais a fim de demonstrar algum fenômeno.

L14 - Modelagem Matemática seria um modelo para descrever algo. Ela surge da necessidade para compreender algo, algum fenômeno. 
Assim como Biembengut e Hein (2000, p.12), entende-se que um modelo matemático é "um conjunto de símbolos e relações matemáticas que traduz, de alguma forma, um fenômeno em questão ou um problema de situação real [...]”. O autor destaca ainda que o modelo matemático que está presente na MM é "a ideia de modelagem suscita a imagem de um escultor trabalhando com argila produzindo um objeto" (BIEMBENGUT; HEIN, 200o, p.11). Para os autores esse objeto retrata uma ideia de modelo, e o resultado do desenvolvimento desse modelo é a modelagem. Isso pode ser inferido nas falas dos alunos acima ao se fazer MM, como algo que se cria ou um modelo para demonstrar ou compreender um fenômeno.

É importante destacarmos ainda que 82\% dos licenciandos que participaram da presente pesquisa, apontaram que nunca tinham realizado uma atividade com MM antes ou durante a graduação. Vejamos algumas falas relacionadas a isso:

L6 - Não, só tinha visto um pouco da teoria.

L9 - Não. Meu ensino Básico foi bastante tradicional, e mesmo no curso só foi apresentada a Modelagem Matemática como metodologia de ensino, mas nunca apresentada de forma prática.

A partir das falas dos licenciandos podemos inferir que a MM até o momento da realização dessas atividades, não era trabalhada como atividade prática no curso de Licenciatura em Matemática, da universidade aqui em estudo. E como destacado pelos licenciandos, a maioria das vezes os professores formadores a apresentam como uma Tendência Matemática que pode ser usada apenas como mais uma metodologia, mas apenas na teoria. Acredita-se que o conhecimento prático faz parte da formação inicial, sendo essencial que o licenciando, futuro professor, tenha o conhecimento matemático também na prática e não somente na teoria. Por isso, é importante que na formação inicial o licenciando tenha contato com materiais e metodologias que possam ser também trabalhados futuramente quando estiver atuando na Educação Básica. A formação inicial deve preparar o futuro professor para encarar os desafios que podem surgir durante a atividade profissional docente, deve também fornecer bases para a construção de um conhecimento pedagógico especializado (IMBERNÓN, 2011).

Assim como Baccon e Arruda (2004), acredita-se que atividades pedagógicas diferenciadas como a MM podem proporcionar um aprendizado mais significativo, bem como possibilitar um novo contexto de relações e sentido na aprendizagem matemática para os alunos.

\section{Considerações finais}

No presente artigo tivemos como objetivo apresentar os resultados de uma ISSN 2526-2882 
experiência com Modelagem Matemática realizada com licenciandos do $3^{\circ}$ ano do Curso de Licenciatura em Matemática da Universidade Estadual de Ponta Grossa. Com as duas atividades de MM desenvolvidas, buscamos estimular os alunos a participarem ativamente nesse processo de aprendizagem e foi possível perceber que houve um grande envolvimento e colaboração dos mesmos.

A principal lição extraída dessa experiência foi a efetividade da metodologia de modelagem matemática em aprimorar o conhecimento matemático utilizado em cada uma das modelagens e a criatividade entre os licenciandos. Foi possível identificarmos ainda que a Modelagem Matemática está presente na formação inicial de professores, de maneira muito tímida ainda, sendo muito pouco trabalhada em sala durante o curso de Licenciatura e, na maioria das vezes, ela ainda é apresentada somente como teoria. Isso nos remete a novos questionamentos como: Quais os motivos ou fatores que levam o professor formador de Matemática a não buscar incorporar novas metodologias em sua ação docente, trabalhando com isso apenas a teoria, protelando a prática sempre para depois?

É preciso pensarmos o ensino no contexto de formação para além da concepção de transmissão de conhecimentos acadêmicos ou a transformação do conhecimento comum em um conhecimento acadêmico, pois a profissão de professor exige outras funções como motivação, participação, animação de grupos, relações sociais com a comunidade e tudo isso requer uma nova formação inicial (IMBERNÓN, 2011).

É necessário ter uma formação que busque novas formas de ensinar, que façam sentido de fato para os alunos. Como vimos no presente artigo, a Modelagem Matemática possibilita um espaço de aprendizagem diferenciado. Por isso, é essencial e indispensável que os licenciandos, futuros professores, tenham a oportunidade de vivenciar atividades desse tipo durante a sua formação. As atividades aqui desenvolvidas apontaram que os discentes em formação ficaram bem interessados com a aplicação da modelagem, mostrando que construíram conhecimentos matemáticos e sobre a metodologia vivenciada.

Acreditamos que apresentar, aplicar e abranger diversas metodologias durante o curso de formação é algo muito positivo e produtivo para que os licenciandos, futuros professores, tenham uma maior experiência com diversas situações que podem ser reproduzidas e vivenciadas também durante a sua atuação docente.

Nossos resultados apontam ainda que é necessário um investimento maior no ensino de metodologias diferenciadas, como a MM nos Cursos de Licenciatura em Matemática, que acabam focando intensamente em uma matemática voltada apenas para o Ensino Superior, sem levar em conta muitas vezes que os licenciandos vão trabalhar no Ensino Básico e que também precisam desses conhecimentos. Novas metodologias são sempre importantes para a complementação do conhecimento do professor, na construção dos seus saberes docentes. 


\section{Referências}

ALMEIDA, L. M. W.; ARAÚJO, J. L., BISOGNIN, E. Práticas de modelagem matemática na educação matemática: relatos de experiência e propostas pedagógicas. Londrina: EDUEL, 2011.

ALMEIDA, L. M. W.; DIAS, M. R. Modelagem Matemática na Licenciatura em Matemática: contribuições para o debate. In: SEMINÁRIO INTERNACIONAL DE PESQUISA EM EDUCAÇÃO MATEMÁTICA, 2., 2003, Santos. Anais... São Paulo: SBEM, 2003. 1 CD-ROM.

BACCON, A. L. P. ARRUDA, S. M. Atividades de modelagem: construindo novos sentidos na aprendizagem em matemática. Anais do I EPMEM. Londrina. 2004.

BARDIN, L. Análise de conteúdo. São Paulo: Edições 70, 2011.

BASSANEZI, R. C. Ensino-Aprendizagem com Modelagem Matemática. São Paulo: Contexto, 2002.

BIEMBENGUT, M. S.; HEIN, N. Modelagem matemática no ensino. São Paulo: Contexto, 2000.

BRASIL, Ministério da Educação e do Desporto. Parâmetros Curriculares Nacionais Matemática. Brasília, 1997.

BURAK, D. Modelagem matemática: uma alternativa para o ensino de matemática na $5^{\mathrm{a}}$ série. Dissertação de Mestrado. Rio Claro, Unesp. 1987.

GIL, A. C. Métodos e técnicas de pesquisa social. 5. ed. São Paulo: Atlas, 1999.

GONÇALVES. M. H. C.; BRITO, M. R. F. aprendizagem de atitudes positivas em relação à matemática. In. BRITO. M. R. F. Psicologia da educação matemática: teoria e pesquisa. Florianópolis: Insular, 2001.

IMBERNÓN, F. Formação docente e profissional: formar-se para a mudança e a incerteza. 8.ed. SP: Cortez, 2011.

KLÜBER, T. E.; BURAK, D. Concepções de modelagem matemática: contribuições teóricas. Pesquisa em Educação Matemática, São Paulo, v. 10, n. 1, p. 17-34. 2008.

MACHADO, A. G. J. Modelagem matemática no ensino-aprendizagem e resultados. Dissertação - Universidade Federal do Pará. Núcleo de Apoio ao Desenvolvimento Científico. Belém. 2005.

MEYER, J. F. C. A. et al. Modelagem em Educação Matemática. Belo Horizonte: Autêntica, 2011.

WALTER, S. A.; BACH, T. M. Adeus papel, marca-textos, tesoura e cola: inovando processo de análise de conteúdo por meio do Atlas.ti. In: SEMEAD, XII, SEMINÁRIOS DE ADMINISTRAÇÃO, 2009, CD, 17 p. São Paulo. Anais, 2009.

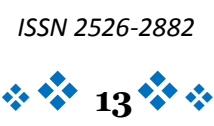


WHITE, E. G. Conselhos aos professores, pais e estudantes. Tatuí: Casa Publicadora Brasileira, 2007.

WHITE, E. G. Educação. Tatuí: Casa Publicadora Brasileira, 2007.

\section{Agradecimentos}

Agradecemos a Danilo Augusto Ferreira de Jesuz, pela confecção do esboço do boneco apresentado nesse artigo na página 4. ALP agradece a professora Dra. Lourdes Maria Werle de Almeida, pela oportunidade de conhecer e trabalhar com a Modelagem Matemática, em sua disciplina ofertada no Mestrado em Ensino de Ciências e Educação Matemática da UEL em 2004, bem como no seu grupo de pesquisa, onde as modelagens citadas no presente artigo foram desenvolvidas.

\section{Biografia Resumida}

Luiz Otávio Rodrigues Mendes: Licenciado em Matemática. Mestrando em Ensino de Ciências e Educação Matemática (PPGCEM) pela UEPG/Universidade Estadual de Ponta Grossa. Pós-Graduando em Educação Inclusiva pela Faculdade Educacional da Lapa (FAEL).

Link Lattes: http://Link Lattes.cnpq.br/8661805143319375

e-mail: mendesluizotavio@hotmail.com

Emilly Gonzales Jolandek: Acadêmica de Licenciatura em Matemática pela Universidade Estadual de Ponta Grossa (UEPG). Professora de Matemática da rede particular de ensino da Escola Adventista de Ponta Grossa (EAPG).

Link Lattes: http://Link Lattes.cnpq.br/5085381393473869

e-mail: emillyjolandek@gmail.com

Ana Lúcia Pereira: Doutora em Ensino de Ciências e Educação Matemática pela Universidade Estadual de Londrina. Professora Adjunta do Departamento de Matemática e Estatística e vinculada aos Programas de Pós-Graduação, Mestrado e Doutorado em Educação e Mestrado em Ensino de Ciências e Educação Matemática na Universidade Estadual de Ponta Grossa ISSN 2526-2882

$$
\text { * } 14 *
$$


(UEPG) - Paraná. Líder do Grupo de Estudos e Pesquisas Políticas Públicas e Formação de Professores - GEPPE. O presente trabalho foi realizado com apoio da CAPES Coordenação de Aperfeiçoamento de Pessoal de Nível Superior Brasil.

e-mail: anabaccon@uepg.br. 